\title{
CHARACTERIZATION OF FECES FOR DESCRIBING THE AEROBIC BIODEGRADATION OF FECES
}

\author{
Miguel Angel LOPEZ ZAVALA ${ }^{1}$, Naoyuki FUNAMIZU ${ }^{2}$ and Tetsuo TAKAKUWA ${ }^{3}$ \\ ${ }^{1} \mathrm{Ph}$ D Student, Dept. of Environmental Eng. Hokkaido University \\ (Kita-13, Nishi-8, Kita-ku, Sapporo 060-8628, Japan) \\ E-mail: lozm@eng.hokudai.ac.jp \\ ${ }^{2}$ Member of JSCE, Dr. Eng., Associate Professor, Dept. of Environmental Eng. Hokkaido University \\ (Kita-13, Nishi-8, Kita-ku, Sapporo 060-8628, Japan) \\ E-mail: funamizu@eng.hokudai.ac.jp \\ ${ }^{3}$ Member of JSCE, Dr. Eng., Professor, Dept. of Environmental Eng. Hokkaido University \\ (Kita-13, Nishi-8, Kita-ku, Sapporo 060-8628, Japan)
}

\begin{abstract}
Characterization of organic matter attending biodegradability is a common practice when a bio-kinetic model is used to describe the reaction rates at which organic matter of wastewater is biodegraded. However, procedures for characterizing organic matter contained in feces have not been reported yet. This paper deals with the characterization of feces; two approaches for characterizing organic matter of feces are discussed based on physicochemical determinations and biological response during aerobic degradation. Application of those procedures leaded to characterization of feces in terms of chemical oxygen demand (COD) and mass units.
\end{abstract}

Key Words: Aerobic biodegradation of feces, characterization of feces, COD, TS and VS

\section{INTRODUCTION}

Bio-toilet is the name of dry closet or composting toilet using sawdust as an artificial soil matrix for bioconversion of human excreta into compost which can be used either as organic fertilizer rich in N, P and $\mathrm{K}$, or as a soil conditioner ${ }^{1), 2}$. The bio-toilet consists mainly of a toilet bowl, composting reactor, ventilation and mixing systems. The composting reactor is filled with sawdust and a button activates the mixer after using the toilet. The human excreta, including toilet paper, are incorporated quietly and odorless into the sawdust matrix where the aerobic biodegradation occurs. Kitsui and Terazawa ${ }^{1)}$ reported that sawdust creates an environment for bacteria thriving since high porosity, high void volume ratio, high water and air retention and high drainage characterize the matrix. The high bacterial tolerance of the woody materials allows the long-time use of sawdust. The low apparent density of sawdust mass saves energy when mixing is performed. However, the key characteristic is the essential biodegradability of sawdust that makes it to be an excellent soil conditioner ${ }^{1)}$.

Performance of the bio-toilet system, and more specifically biodegradation rates, is affected by several factors, including the substrate bio- availability that is mainly associated with the biodegradability of organic matter contained in feces. Composition of human excrement shows a wide range of variability from person to person and place to place. Del Porto and Steinfeld ${ }^{2}$ collected information from several studies related with human excrement and summarized values of several parameters mainly associated with the organic load and content of nutrients. However, that information does not allow the evaluation of biodegradability of organic matter contained in feces.

Characterization of organic matter attending biodegradability is a common practice when a bio-kinetic model is used to describe the reaction rates at which organic matter is biodegraded. Procedures to characterize organic matter in wastewater have been already developed, some of them based on respirometry and performance of batch tests ${ }^{3), 4), 5}$. However, procedures for characterizing organic matter contained in feces have not been reported yet, so that, development of them is needed because feces composition influences the treatment performance in a degree similar to that of the system design.

Modeling and simulation are working tools that can be used not only for describing kinetics of aerobic biodegradation of toilet wastes, but also for 
proper design and operation of the treatment systems. The quality of model predictions depends on the quality of the feces characterization and on the calibration of the model. The planned use of modeling results determines the degree of complexity needed in the characterization.

Under above considerations, this paper deals with the characterization of feces; two approaches for characterizing organic matter of feces are discussed based on measurements of physicochemical parameters and biological response during aerobic degradation.

\section{METHOD}

Characterization of feces has been traditionally carried out regarding the concentration of different constituents or values of several parameters that indicate in certain way the organic load and nutrient availability. However, this way of characterizing feces does not allow judging the biodegradability of organic matter contained in feces.

On the other hand, in activated sludge literature ${ }^{4), 5), 6), 7)}$, organic matter has been divided into two main fractions attending its biodegradable character, non-biodegradable and biodegradable organic matter. The non-biodegradable organic matter has two sub-fractions, particulate and soluble. The biodegradable organic matter has also two sub-fractions, slowly biodegradable particulate and readily biodegradable soluble. This division has been made based on biological response, not on physical separation ${ }^{4), 5), 6), 7)}$. Thus, biodegradability of feces may be assessed attending this way of characterizing organic matter.

Above fractioning can be determined through the performance of simple batch tests; measuring the chemical oxygen demand (COD); monitoring the oxygen utilization rate (OUR) and simulating OUR profiles. Additionally, biodegradability may be assessed in terms of mass units by measuring simple physical parameters such as total solids (TS) and volatile solids (VS).

\section{(1) Experimental device}

Fig.1 shows the experimental device employed for performing batch tests. Four bioreactors, constructed of glass and steel, and provided with steel porous plate in the bottom for ensuring well distribution of air supply, were placed into water baths; sensors for oxygen, temperature and pressure were set before and after the bioreactor, and an additional temperature sensor was also placed inside of it; all of them were properly connected to a computer for monitoring. Air was supplied into the

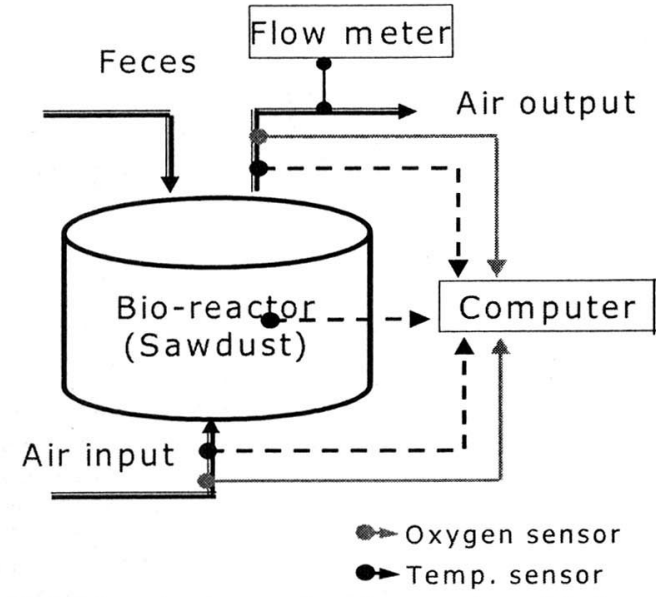

Fig.1 Schematic representation of the experimental device.

Table 1 Experimental conditions set up for batch tests performance.

\begin{tabular}{cccccc}
\hline F/S $^{1}$ & $\begin{array}{c}\text { TS } \\
\text { feces }^{2} \\
(\mathbf{g})\end{array}$ & $\begin{array}{c}\text { TS } \\
\text { sawdust }^{2} \\
(\mathbf{g})\end{array}$ & $\begin{array}{c}\text { Feces } \\
\text { moisture } \\
\text { content } \\
(\%)\end{array}$ & $\begin{array}{c}\text { Mixture } \\
\text { moisture } \\
\text { content } \\
(\%)\end{array}$ & $\begin{array}{c}\text { Air flow } \\
\text { rate } \\
(\mathbf{m l} / \mathbf{m i n})\end{array}$ \\
\hline 5 & 6.3 & 125.0 & 80.4 & 60.0 & 50.0 \\
10 & 12.5 & 125.0 & 84.7 & 60.0 & 50.0 \\
15 & 18.8 & 125.0 & 73.4 & 60.0 & 50.0 \\
25 & 31.2 & 125.0 & 83.8 & 60.0 & 100.0 \\
\hline
\end{tabular}

$1 \mathrm{~F} / \mathrm{S}$ ratios (on dry basis) were fixed based on experimental results reported by Terazawa ${ }^{8}$.

2 TS: Total solids expressed on dry basis.

bioreactor continuously and air flow rate and pressure were controlled and kept constant by using a flow meter. Air was dried before measuring oxygen concentrations by using silica gel. Bioreactors were submerged into water whose temperature was kept constant by using a temperature controller. Oxygen utilization rates were computed based on measurements of oxygen concentrations of air before and after the bioreactor.

\section{(2) Batch tests}

Batch tests for four different feces/sawdust ratios (F/S: $5,10,15$ and $25 \%$, on dry basis) were conducted at $55^{\circ} \mathrm{C}$ and under the conditions described in Table 1 . Feces were properly mixed into the sawdust for ensuring uniform and completely mixed conditions. All mixtures were set up at $60 \%$ of initial moisture content by adding distilled water. Enough air was supplied in each trial for keeping perfect aerobic conditions; air flow rates and pressure were kept constant during the tests performance. Input and output oxygen concentrations were monitored every 20 minutes and the corresponding TS, VS and COD and moisture content of feces, sawdust and compost 
were measured in all trials. OUR was computed in every trial based on input and output oxygen concentrations.

\section{(3) Characterization based on COD}

COD is undoubtedly the superior measure of the concentration of organic material because it alone provides a link between electron equivalents in the organic substrate, the biomass and oxygen utilized. Furthermore, mass balance can be made in terms of $\mathrm{COD}^{6)}$. When characterization is thought for modeling purposes, it is important to note that there is a close relationship between characterization of feces and the model and constants used. The quality of characterization may be evaluated based on biological response (oxygen consumption) during biodegradation, so that, the level of fractioning will be given by modeling and simulating the oxygen utilization rate. Thus, the most proper characterization will be the one that allows better model predictions.

The total organic matter contained in feces can be measured as COD, which can be divided depending on the complexity and the use of the model. Fig.2 shows the hypothetical composition of feces based on the fractioning presented above; as depicted, it is assumed that feces are composed of biologically inert material or non-biodegradable particulate $\left(X_{I}\right)$ and biodegradable organic matter which is subdivided into readily biodegradable organic matter $\left(S_{S}\right)$ and slowly biodegradable organic matter $\left(X_{S}\right)$. During biodegradation, it is also assumed that $X_{S}$ is transformed into readily biodegradable organic matter $\left(S_{S}\right)$ by hydrolysis; growth of heterotrophic biomass $\left(X_{H}\right)$ occurs at expense of $S_{S}$ associated with oxygen utilization; under the death-regeneration approach ${ }^{6)}$, decaying biomass is split into two fractions: inert matter $\left(X_{I P}\right)$ and slowly biodegradable matter $\left(X_{S}\right)$; the latter is subsequently hydrolyzed into readily biodegradable substrate. The death-regeneration model implies that, even when all the substrate originating from the feces has been oxidized, there remains an oxygen consumption associated with the growth on substrate released from decay. The amount of new biomass formed from released substrate is always less than the amount of biomass lost ${ }^{6)}$. If the oxygen consumption rate at this stage is quite low, approximating toward to the initial level, it might be able to assume that the fraction associated to biomass is negligible and only two fractions of inert material remain in the experimental bioreactor.

According to Fig.2, the total COD of feces includes the following components

$$
T C O D=X_{I}+S_{S}+X_{S}
$$

On the other hand, the total biologically inert

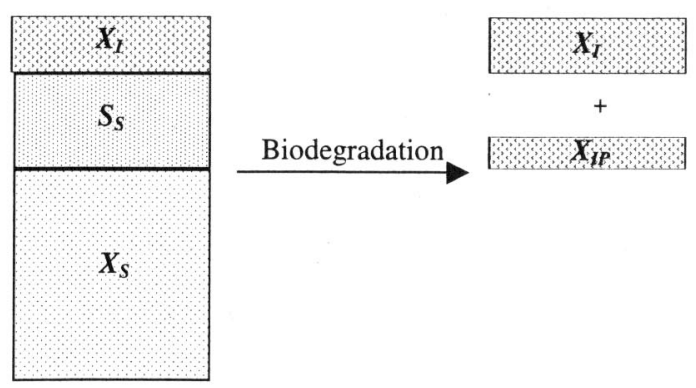

Fig.2 Hypothetical composition of feces in terms of COD.

material remaining in the experimental reactor (XIT) can be expressed as follows:

$$
X_{I T}=X_{I}+X_{I P}=X_{I}+Y_{H}\left(S_{S}+X_{S}\right) f_{X I}
$$$$
\text { where }
$$

$X_{I T}=$ total biologically inert material that remains in the experimental reactor, g COD.

$Y_{H}=$ yield coefficient for heterotrophic biomass, $\mathrm{g}$ COD $(\mathrm{g} \mathrm{COD})^{-1}$.

$f_{X I}=$ inert $\mathrm{COD}$ production coefficient in endogenous respiration, g COD $(\mathrm{g} \mathrm{COD})^{-1}$.

$Y_{H}\left(S_{S}+X_{S}\right)=$ quantity of biodegradable organic matter that is converted into biomass, g COD.

Substituting equation (1) in equation (2) and rearranging terms yields

$$
S_{S}+X_{S}=\frac{T C O D-X_{\mathrm{IT}}}{1-Y_{H} f_{X I}}
$$

Estimation of $S_{S}$ and $X_{S}$ requires the prior determination of stoichiometric parameters such as biomass yield coefficient $Y_{H}$ and the inert COD production coefficient in endogenous respiration $f_{X I}$. Estimation of them constitutes a real challenge due to the difficulty for measuring directly the biomass growth in the sawdust matrix; so that, conservative values of these parameters were adopted from those reported in the literature of activated sludge systems, mainly determined at $20^{\circ} \mathrm{C}$. Regarding the uncertainty associated with the impact of temperature on yield coefficient, most engineers assume it to be independent of temperature ${ }^{9)}$. Thus,

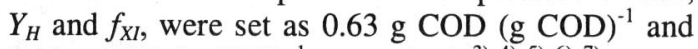
$0.10 \mathrm{~g} \mathrm{COD}\left(\mathrm{g} \mathrm{COD}^{-1}\right.$ respectively $^{3), 4), 55,6), 7)}$.

Even though, organic matter was assumed to be composed of three fractions in Fig.2, modeling and simulating the oxygen utilization rate give the most convenient level of fractioning. The most proper characterization is that which allows better model predictions. Thus, the level of fractioning and estimation of fractions $X_{I}, S_{S}$ and $X_{S}$ are determined regarding two cases.

a) Case I: Feces constituted only by $X_{I}$ and $X_{S}$

This case assumes that all biodegradable organic matter contained in feces corresponds to slowly 
biodegradable $\left(X_{S}\right)$; so that, equations (1) and (3) are simplified as follows

$$
\begin{gathered}
\text { TCOD }=X_{I}+X_{S} \\
X_{S}=\frac{T C O D-X_{\mathrm{IT}}}{1-Y_{H} f_{X I}}
\end{gathered}
$$

Based on COD reductions observed during batch tests performance for every $\mathrm{F} / \mathrm{S}$ ratio, the fraction of total biologically inert material $\left(X_{I T}\right)$ remaining in the experimental reactor is estimated. Thus, substituting this known term and values of $Y_{H}$ and $f_{X I}$ in equation (5), fractions $X_{S}, X_{I}$ and $X_{I P}$ are determined from equations (5), (4) and (2) respectively.

b) Case II: Feces composed of three fractions $X_{I}$, $S_{S}$ and $X_{S}$

This case assumes that biodegradable organic matter contained in feces may be divided into $S_{S}$ and $X_{S}$ as shown in Fig.2. Thus, equation (3) can be expressed as follows:

$$
X_{S}=\frac{T C O D-X_{\mathrm{IT}}}{1-Y_{H} f_{\mathrm{XI}}}-S_{S}
$$

Regarding the OUR profile shown in Fig.3 and applying the method developed by Kappeler and Gujer $^{5)}$ for characterizing wastewater, the OUR increases and decreases rapidly because the consumption of readily biodegradable organic matter leads to substrate limitation. Once nearly all readily biodegradable substrate is used, the oxygen respiration is dominated by growth on substrate released by hydrolysis and less by endogenous respiration ${ }^{5}$. Therefore, the fraction $S_{S}$ is equivalent to the term $A /\left(1-Y_{H} f_{X I}\right)$, where $A$ is the area under the OUR profile defined by the peak and the baseline-respiration as depicted in Fig.3; thus, equation (6) is transformed in

$$
X_{S}=\frac{T C O D-X_{I T}}{1-Y_{H} f_{X I}}-\frac{A}{1-Y_{H} f_{X I}}
$$

Using the experimental OUR profiles, the area $A$ is estimated for every $\mathrm{F} / \mathrm{S}$ ratio. The resting terms of right side of the equation (7) are known, therefore, fractions $X_{S}, X_{I}$ and $X_{I P}$ are determined from equations (7), (1) and (2) respectively.

The applicability and feasibility of both fractioning levels, considered in cases I and II, are evaluated by comparison between model predictions and experimental data. The simulation program developed by Lopez et al. ${ }^{10)}$ is used for this purpose.

\section{(4) Characterization based on mass units}

Knowledge of the amount and character of the compost produced during the aerobic biodegradation of feces allows proper design and operation of the bio-toilet system, since quantity of remaining residue is increasing with the time and the composition of such residue determine the

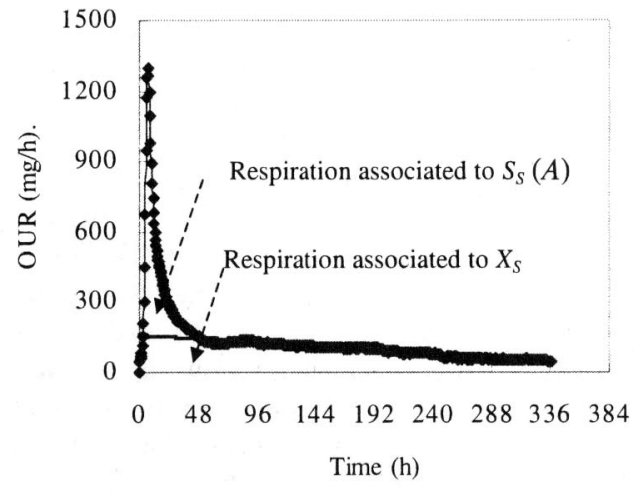

Fig.3 Oxygen respiration rate.

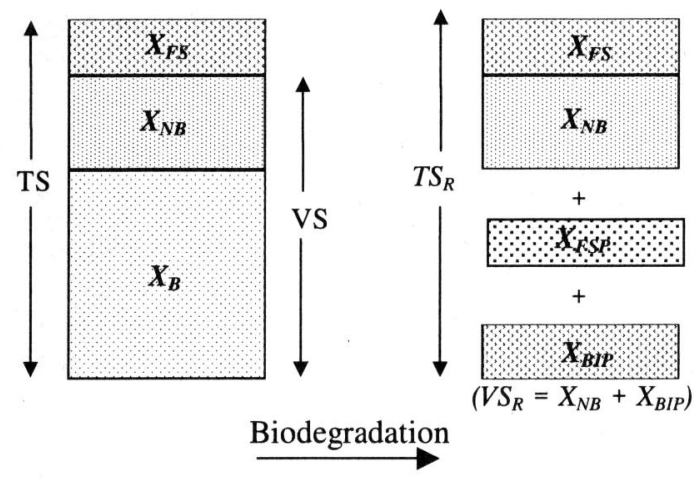

Fig.4 Hypothetical composition of feces in terms of mass units.

quality of the compost generated. Characterization of feces based on mass units may be an affordable way for evaluating the quantity and composition of the residue accumulated in the composting reactor. Fig.4 shows the hypothetical composition of feces regarding mass units $(\mathrm{g})$, as depicted, it is assumed that feces are composed by fixed solids $\left(X_{F S}\right)$ that are biologically inert, non-biodegradable volatile solids $\left(X_{N B}\right)$ that are also biologically inert and biodegradable volatile solids $\left(X_{B}\right)$ which are used by heterotrophic biomass to growth; fixed solids $\left(X_{F S}\right)$, and non-biodegradable volatile solids $\left(X_{N B}\right)$ remain in the composting reactor without any transformation. During biodegradation, fixed solids production $\left(X_{F S P}\right)$ occurs since some chemical species $(S, P)$ contained in feces change to their oxidized form trapping oxygen in their molecular structure $^{11)}$. Biologically inert volatile solids $\left(X_{B I P}\right)$ are produced in endogenous respiration and, besides $X_{F S P}$, remain in the composting chamber. Thus, the total mass of feces solids (TS) includes the following components

$$
T S=X_{F S}+\left(X_{N B}+X_{B}\right)
$$

And the total mass of solids remaining in the 
experimental reactor encompasses

$$
T S_{R}=\left(X_{F S}+X_{F S P}\right)+\left(X_{N B}+X_{B I P}\right)
$$

$X_{F S}$ is estimated gravimetrically on the base of total solids and volatile solids measurements as follows

$$
X_{F S}=T S-V S
$$

where $T S$ and $V S$ are expressed in mass units (g).

On the other hand, the total mass of remaining volatile solids $\left(V S_{R}\right)$ may be expressed as follows where

$$
V S_{R}=X_{N B}+X_{B I P}=X_{N B}+Y_{H}^{\prime}\left(X_{B}\right) f^{\prime}{ }_{X I}
$$

$Y_{H}^{\prime}=Y_{H}$ expressed in g VS (g VS) $)^{-1}$.

$f^{\prime}{ }_{X I}=f_{X I}$ expressed in $\mathrm{g}$ VS $(\mathrm{g} \mathrm{VS})^{-1}$.

$Y_{H}^{\prime}\left(X_{B}\right)=$ quantity of biodegradable volatile solids that is converted into biomass, $g$ VS.

Substituting $V S=X_{N B}+X_{B}$ in equation (11) yields

$$
X_{B}=\frac{V S-V S_{\mathrm{R}}}{1-Y^{\prime}{ }_{H} f^{\prime}{ }_{X I}}
$$

Then, $X_{N B}$ and $X_{B I P}$ are computed from equation (11).

Estimation of $X_{B}$ requires the prior determination of the stoichiometric parameters $Y_{H}^{\prime}$ and $f_{X I}^{\prime}$. Those values adopted in COD characterization may be used by expressing them in mass units, $g$ VS ( $g$ $V S)^{-1}$. Conversion factors are used for that purpose.

As seen, it is not required to know $X_{F S P}$ for estimating the fractions that constitute feces; however, it can be determined as follows

$$
X_{F S P}=T S_{R}-V S_{R}-X_{F S}
$$

\section{RESULTS AND DISCUSSION}

\section{(1) Feces content}

There is a wide range of variability in the content of feces from person to person and place to place. Factors such as nutrition, climate, health, age and lifestyle are responsible of that variability. In this respect, from the analysis of 26 feces samples, Table 2 shows average values for some parameters that indicate in certain way the organic load and nutrient availability of feces. Data of moisture content, TS and COD are in accordance with those reported by other researchers ${ }^{12)}$. As seen, approximately $82 \%$ of water and $18 \%$ of solids constitute feces. $84 \%$ of solids are volatile solids (organic material) and $16 \%$ are fixed solids (inorganic material). Fixed solids and non-biodegradable VS remained in the experimental reactor without any transformation.

\section{(2) Characterization in terms of COD}

For easier comparisons, all values of fractions shown below were expressed in decimal fractions (relative values respect to TCOD).
Table 2 Pollution load of excrement.

\begin{tabular}{cccc}
\hline Parameter & Unit & Average & Almeida et al. ${ }^{\mathbf{1}}$ ) \\
\hline Moisture & $\%$ & 81.8 & 79.2 \\
$\mathrm{TS}$ & $\%$ & 18.2 & 20.8 \\
$\mathrm{VS}$ & $\%$ & 84.4 & - \\
$\mathrm{pH}$ & - & 7.5 & - \\
$\mathrm{EC}$ & $\mu \mathrm{S} / \mathrm{cm}$ & 115.9 & - \\
$\mathrm{COD}$ & $\mathrm{mg} / \mathrm{mg}$ & 1.45 & 1.38 \\
$\mathrm{NH}_{3}-\mathrm{N}$ & $\mathrm{mg} / \mathrm{g}$ & 3.4 & 7.2 \\
$\mathrm{~T}-\mathrm{N}$ & $\mathrm{mg} / \mathrm{g}$ & 60.1 & - \\
$\mathrm{NO}_{3}-\mathrm{N}$ & $\mathrm{mg} / \mathrm{g}$ & 0.03 & 0.14 \\
$\mathrm{Cl}$ & $\mathrm{mg} / \mathrm{g}$ & 4.2 & - \\
$\mathrm{SO}_{4}$ & $\mathrm{mg} / \mathrm{g}$ & 1.1 & - \\
$\mathrm{PO}_{4}-\mathrm{P}$ & $\mathrm{mg} / \mathrm{g}$ & 4.5 & 27.9 \\
\hline $\mathrm{Hin}_{4} \mathrm{H}$
\end{tabular}

Units in mass/mass are expressed on dry basis.

Table 3 Estimation of $X_{S} / T C O D$.

\begin{tabular}{cccc}
\hline $\begin{array}{c}\text { F/S } \\
(\%)\end{array}$ & $\begin{array}{c}\text { TCOD } \\
(\mathrm{g})\end{array}$ & $\begin{array}{c}\boldsymbol{A} \\
(\mathrm{g})\end{array}$ & $\boldsymbol{X}_{\boldsymbol{S}} / \mathbf{T C O D}$ \\
\hline 5 & 9.0 & 2.00 & 0.56 \\
10 & 18.7 & 5.93 & 0.46 \\
15 & 29.3 & 7.99 & 0.51 \\
25 & 44.4 & 10.96 & 0.54 \\
\hline \multicolumn{3}{c}{ Average } & 0.52 \\
\hline
\end{tabular}

a) Case I

Lopez et $a l .{ }^{13)}$ evaluated the effect of organicloading on the aerobic biodegradation of feces using sawdust as a matrix, they found that the fraction of total biologically inert material $\left(X_{I T}\right)$ remaining in the experimental reactor after biodegradation was $25 \%$. Substituting this value and those adopted for stoichiometric parameters in equation (5) yields

$$
\frac{X_{S}}{T C O D}=\frac{1-X_{I T} / T C O D}{1-Y_{H} f_{X I}}=\frac{1-0.25}{1-0.63 * 0.10}=0.80
$$

Therefore, from equations (4) and (2) the values of following fractions were obtained

\section{b) Case II}

$$
\begin{gathered}
\frac{X_{I}}{T C O D}=0.20 \text { and } \\
\frac{X_{I P}}{T C O D}=0.05
\end{gathered}
$$

Based on the experimental OUR profiles obtained from the batch tests, the area $A$ associated to $S_{S}$ was determined for every $\mathrm{F} / \mathrm{S}$ ratio. Replacing terms of equation (7) per their respective values, $X_{S}$ was obtained as follows

$$
\frac{X_{S}}{T C O D}=\frac{1-0.25}{1-0.63 * 0.10}-\frac{2.0 / 9.0}{1-0.63 * 0.10}=0.56
$$

Calculations for other trials are summarized in Table 3. As seen, the average value of the slowly 
biodegradable fraction was

$$
\frac{X_{s}}{T C O D}=0.52
$$

Substituting this value into equation (6) yields

$$
\frac{S_{S}}{T C O D}=\frac{1-0.25}{1-0.63 * 0.10}-0.52=0.28
$$

Therefore, from equations (1) and (2) the values of following fractions were obtained

$$
\begin{gathered}
\frac{X_{I}}{T C O D}=0.20 \text { and } \\
\frac{X_{I P}}{T C O D}=0.05
\end{gathered}
$$

The applicability and feasibility of above fractions for both cases were confirmed through comparison between model predictions and experimental data; thus, the OUR profile for every $\mathrm{F} / \mathrm{S}$ ratio was simulated regarding the fractioning level of both cases. Fig.5 shows the simulation results for the $\mathrm{F} / \mathrm{S} 15 \%$, it is clear that the best curve fitting is given by the case I; the simulated OUR profile fitted properly to that experimentally obtained not only for this $\mathrm{F} / \mathrm{S}$ ratio but also for the others; therefore, fractioning of feces COD into two categories, biologically inert material $X_{I}$ and slowly biodegradable organic matter $X_{S}$ (case $\mathrm{I}$ ), is applicable and affordable for characterizing feces.

\section{(3) Characterization in terms of mass units}

For easier comparisons, all values of fractions shown below were expressed in decimal fractions (relative values respect to TS). As shown in Table 2, volatile solids constitute approximately $84 \%$ of feces; therefore, from equation (10) the fraction $\left(X_{F S}\right)$ was computed as $16 \%$.

The conversion factor VS to biomass was estimated as $0.76 \mathrm{~g}$ VS (g COD) ${ }^{-1}$ from activated sludge literature ${ }^{77}$. Based on VS and COD measurements, the conversion factor VS to substrate was approximately $0.58 \mathrm{~g}$ VS (g COD) $)^{-1}$ and adopting same ratio for VS to $X_{B I P}$, the stoichiometric parameters expressed in mass units yields

$$
\begin{gathered}
Y_{{ }_{H}}^{\prime}=0.48{\mathrm{~g} \mathrm{VS}(\mathrm{g} \mathrm{VS})^{-1} \text { and }}^{\prime}{ }^{\prime}{ }_{X I}=0.13 \mathrm{~g} \mathrm{VS}(\mathrm{g} \mathrm{VS})^{-1}
\end{gathered}
$$

On the other hand, Lopez et al. ${ }^{13)}$ found that approximately $70 \%$ of feces VS was depleted during batch test performance. Substituting this value and those for stoichiometric parameters in equation (12) yields

$$
\frac{X_{B}}{T S}=\frac{\left(V S-V S_{R}\right) / T S}{1-Y_{H}^{\prime} f^{\prime}{ }_{X I}}=\frac{0.84 * 0.70}{1-0.48 * 0.13}=0.63
$$

Hence, from equation (11) the values of following fractions were computed

$$
\frac{X_{B I P}}{T S}=0.48 * 0.63 * 0.13=0.04 \text { and }
$$

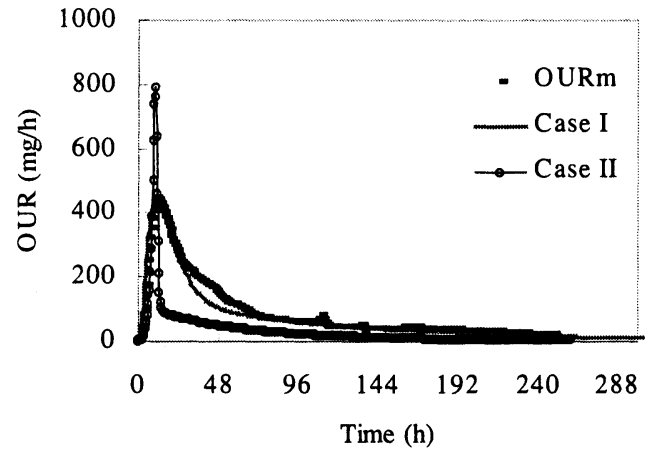

Fig.5 Simulation of OUR for two feces fractioning levels

$$
\frac{X_{N B}}{T S}=0.84 * 0.30-0.04=0.21
$$

Lopez et al. ${ }^{13)}$ also found that total solids remaining in the experimental bioreactor $\left(T S_{R}\right)$ counted approximately $44 \%$; thus, substituting these values in equation (13) yields

$$
\frac{X_{F S P}}{T S}=0.44-0.84 * 0.30-0.16=0.03
$$

Fig.6 summaries schematically the results obtained by applying the two methods of characterizing feces. Characterization based on mass units may be useful for assessing the quantity and character of residue that accumulates in the composting reactor of bio-toilet systems, whereas characterization of feces based on COD measurements is convenient for modeling purposes, technique that allows the establishment of criteria for the proper design and operation of bio-toilet systems.

\section{CONCLUSIONS}

Characterization of feces for bio-toilet systems using sawdust as a matrix was conducted attending the biodegradability of organic matter contained in feces. Two methods were used for that purpose, the first expressed in terms of COD, where COD measurements, experimental OUR profiles and simulation were used. Whereas, in the second, expressed in terms of mass units, measurements of physical parameters such as TS and VS were employed.

In terms of COD, feces were characterized into two fractions, biologically inert material $20 \%$ and slowly biodegradable organic matter $80 \%$. Characterization in these terms is useful for modeling purposes, which is essential for establishing criteria for the proper design and operation of bio-toilet systems. 


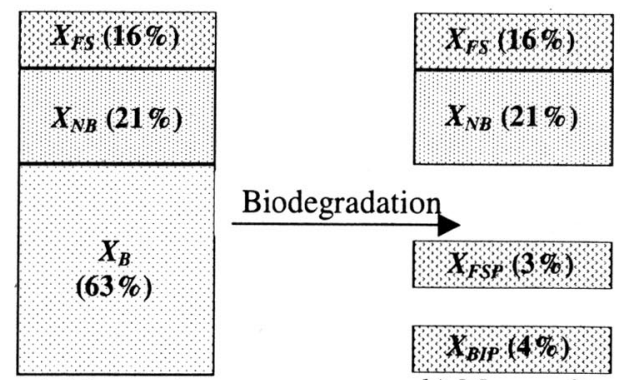

a) Mass units

b) Mass units

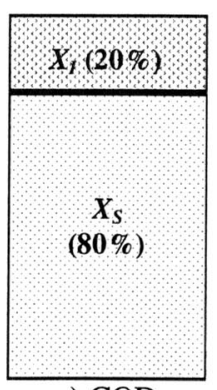

c) COD $x_{1}(20 \%)$

$\stackrel{\text { Biodegradation }}{\longrightarrow}$

$X, 5 \%$

d) $\mathrm{COD}$

Fig.6 Theoretical composition of feces and its transformation during biodegradation

Regarding mass units, feces were characterized into three fractions, fixed solids $16 \%$, non-biodegradable volatile solids $21 \%$ and biodegradable volatile solids $63 \%$. Characterization of feces in these terms is affordable for evaluating the quantity and composition of the residue accumulated in the composting reactor that interferes in the design and operation of the bio-toilet system.

ACKNOWLEDGEMENTS: We thank Mr. Toshihiro Kitsui (Seiwa Denko Inc.) who provided us sawdust samples from bio-toilets under operation.

\section{REFERENCES}

1) Kitsui, T. and Terazawa, M.: Environmentally-friendly toilets for the $21^{\text {st }}$ century, Bio-toilet. Procedings of the $10^{\text {th }}$ ISWPC, at Yokohama, III, pp 120-121, 1999.

2) Del Porto, D. and Steinfeld, C.: The composting toilet system book. Center for Ecological Pollution Prevention (CEPP). Concord Massachusetts, 1998.

3) Vanrolleghem, P. A., Spanjers, H., Petersen, B., Ginestet, P. and Takacs, I.: Estimating (combination of) Activated Sludge Model No. 1 parameters and components by respirometry. Wat. Sci. Tech. Vol. 39, No. 1, pp. 195-214, 1999.

4) Spanjers, H. and Vanrolleghem, P. A.: Respirometry as a tool for rapid characterization of wastewater and activated sludge. Wat. Sci. Tech. Vol. 31, No. 2, pp. 105-114, 1995.
5) Kappeler, J. and Gujer, W.: Estimation of kinetic parameters of heterotrophic biomass under aerobic conditions and characterization of wastewater for activated sludge modeling. Wat. Sci. Tech. Vol. 25, No. 6, pp. 125-139, 1992.

6) Henze, M., Grady, C. P. L. Jr., Gujer, W., Marais, G. v. R. and Matsuo, T.: Activated Sludge Model No. 1. IAWPRC Scientific and Technical Reports, No. 1, IAWQ, London, 1987.

7) Gujer, W., Henze, M, Mino, T. and Van Loosdrecht, M.: Activated Sludge Model No. 3. Wat. Sci. Tech.; Vol. 39, No. 1, pp 183-193. 1999

8) Terazawa, M.: Ability of sawdust as an artificial soil. Division of Environmental Resources, Graduate School of Agriculture, Hokkaido University, Japan, 1995.

9) Grady, C. P. L., Daigger, G. T. and Lim, H. C.: Biological wastewater treatment. 2nd Edition, Marcel Dekker, Inc. USA, 1999.

10) Lopez Zavala, M. A., Funamizu, N. and Takakuwa, T.: Modeling of aerobic biodegradation of feces using sawdust as a matrix. Submitted. 2002.

11) Terazawa, M.: New plan and perspective on agricultural resource recycling system. Division of Environmental Resources, Graduate School of Agriculture, Hokkaido University, Japan (in Japanese), 1993.

12) Almeida, M.C, Butler, D. and Friedler, E.: At-source domestic wastewater quality. Wat. Sci. Tech. Urban Water 1, pp 49-55, 1999.

13) Lopez Zavala, M. A., Funamizu, N. and Takakuwa, T: Organic load influence on aerobic biodegradation of feces by using sawdust as a matrix. Proceedings Asian Waterqual 2001, Fukuoka, Japan, 2001.

(Received March 4, 2002) 